10.2

\title{
Экспериментальное исследование перестраиваемого акустического фазовращателя
}

\author{
(C) А.А. Невзоров, С.В. Перченко ", Д.А. Станкевич \\ Волгоградский государственный университет, Волгоград, Россия \\ ๑ E-mail: perchenko@volsu.ru
}

Поступило в Редакцию 1 апреля 2021г.

В окончательной редакции 3 мая 2021 .

Принято к публикации 4 июня 2021 г.

\begin{abstract}
Приводятся результаты численного и экспериментального исследования акустического фазовращателя на основе цепочки прямоугольных резонаторов Гельмгольца. Регулирование фазы прошедшей акустической волны осуществляется путем одновременного изменения объемов резонаторов с помощью шагового двигателя. В результате эксперимента установлено, что разработанный акустический фазовращатель позволяет манипулировать фазовым сдвигом волны в пределах $0-2 \pi$ в диапазоне частот $2000-2500 \mathrm{~Hz}$, при этом изменение амплитуды давления на выходе составляет не более $30 \%$. Фазовращатель может быть использован в качестве ячейки перестраиваемой акустической метаповерхности.
\end{abstract}

Ключевые слова: акустика, управление волной, фазовращатель, метаповерхность.

DOI: 10.21883/PJTF.2021.18.51464.18798

Акустические метаповерхности являются актуальной темой современных исследований, так как они позволяют эффективно осуществлять преломление [1], отражение [2], фокусировку [3], поглощение [4] и изменение волнового фронта [5] акустических волн. Основой метаповерхности обычно является набор ячеек, позволяющих изменять фазу прошедшей волны на заданную величину, например, из дискретного набора $n \pi / 4$, где $n=0-7$. Основным недостатком рассмотренных фазовращателей является их статическая конструкция, поэтому изготовленные на их основе метаповерхности могут выполнять только одну функцию (например, преломлять нормально падающую волну фиксированной частоты на заданный угол). По этой причине активно исследуются перестраиваемые акустические фазовращатели.

В работе [6] рассматривается перестраиваемая метаповерхность, в качестве ячеек которой используются винтовые фазовращатели. Изменяя глубину вворачивания винта, удалось добиться изменения фазы прошедшего излучения на $2 \pi$. Коэффициент пропускания при этом имеет сильно резонансный характер и не превышает 0.8. В [7] в качестве ячеек метаповерхности используются сегменты тонкостенных полых цилиндров. Показаны фокусировка и расфокусировка волны с фокусным расстоянием порядка поперечного размера метаповерхности. Часто рассматриваются перестраиваемые метаповерхности на основе резонаторов Гельмгольца. В [8] для перестройки резонатора в его объем подается жидкость, в [9] одновременно изменяются объем резонатора и сечение волноведущей трубы. В обеих работах показано хорошее согласие экспериментальных данных и результатов численного моделирования на примере фокусировки и преломления волны. Отметим, что изменение объема резонатора в [9] осуществляется вручную.

Главной проблемой современных управляемых метаповерхностей являются сложность и низкая скорость перестройки их фазовращателей. Использование жидкостных ячеек [8] требует сложной гидравлической системы управления и повышенной герметичности, а конструкции в работах $[6,7]$ из-за своей геометрии затрудняют использование электрически управляемых систем перемещения. Кроме того, в работе [8] для полного поворота фазы требуется $\sim 25 \mathrm{~s}$. Далее рассмотрим акустический фазовращатель на основе резонаторов Гельмгольца, допускающих оперативное изменение объема резонатора с помощью шагового двигателя.

Схематическое изображение установки для экспериментального исследования акустического фазовращателя приведено на рис. 1. Для возбуждения акустической волны был выбран миниатюрный электродинамический громкоговоритель CNS3508A075BER (CANOPUS) c эллиптическим диффузором. Передача акустической волны от громкоговорителя к фазовращателю и нагрузке осуществляется через прямоугольный акустический волновод с внутренним сечением $33 \times 19 \mathrm{~mm}$. В качестве нагрузки выходного волновода используется катеноидальный рупор прямоугольного сечения длиной $160 \mathrm{~mm}$ с размерами устья $160 \times 160 \mathrm{~mm}$ с граничной частотой среза $\sim 900 \mathrm{~Hz}$, который согласует импеданс волновода и открытого пространства. Во входном и выходном волноводах предусмотрены по два фланца для подключения измерительных микрофонов, располагающиеся на расстояниях 20 и $60 \mathrm{~mm}$ от фазовращателя. Численное моделирование показало, что на указанных расстояниях в диапазоне частот $1-10 \mathrm{kHz}$ в волноводе будет присутствовать только поршневая мода. 


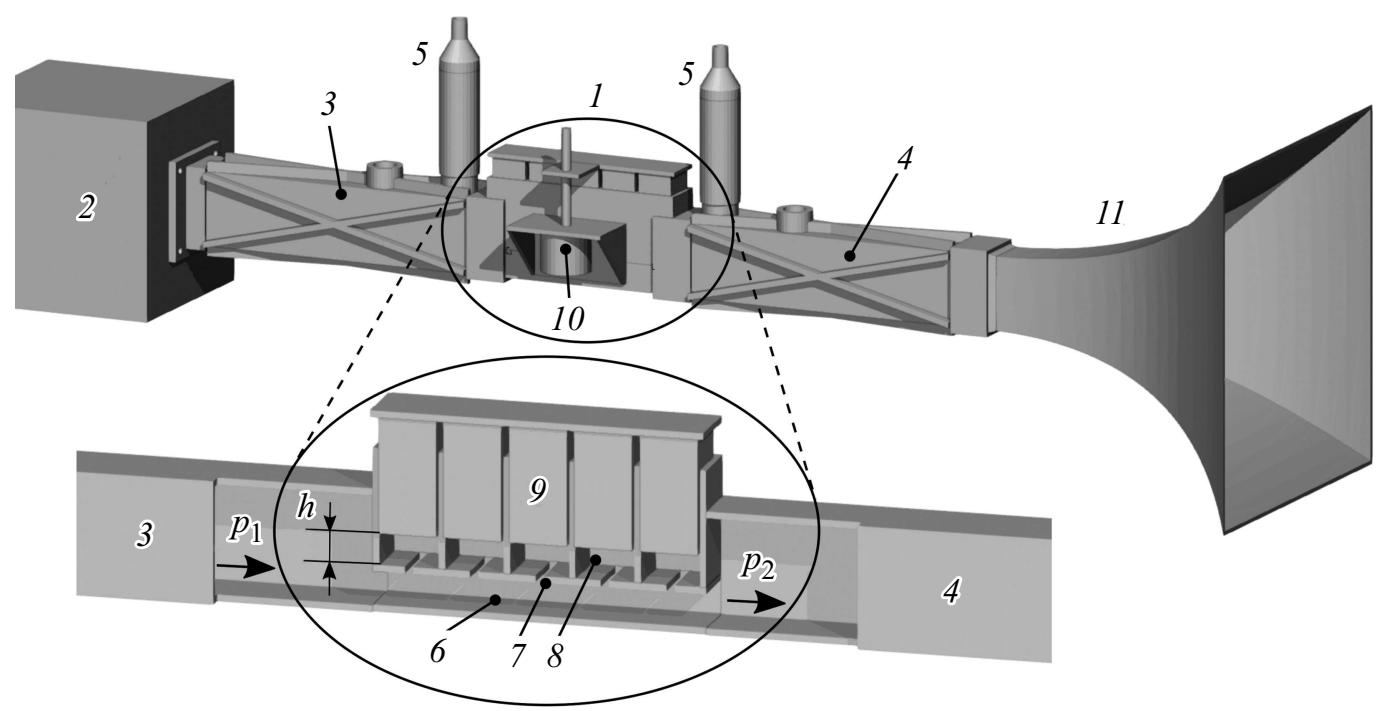

Рис. 1. Схематическое изображение экспериментальной установки. 1 - фазовращатель в сборе; 2 - излучатель в корпусе; 3,4 - входной и выходной волноводы; 5 - микрофоны; 6 - волновод фазовращателя; 7 - горловина резонатора; 8 - полость резонатора; 9 - подвижные поршни; $10-$ шаговый двигатель; $11-$ согласующий рупор.

Фазовращатель состоит из волноведущей прямоугольной трубы с внутренним сечением $10 \times 19 \mathrm{~mm}$, толщиной стенок $2 \mathrm{~mm}$ и длиной $L_{p}=100 \mathrm{~mm}$. К трубе через прямоугольную горловину сечением $2.5 \times 19 \mathrm{~mm}$ подключены пять резонаторов Гельмгольца прямоугольной формы сечением $17.5 \times 19 \mathrm{~mm}$ и глубиной $35 \mathrm{~mm}$. В результате численного моделирования установлено, что использование меньшего числа резонаторов в указанной конструкции не позволит добиться фазового сдвига $2 \pi$. В работах $[1,9]$ показано, что при уменьшении сечения волноведущей трубы при неизменной высоте резонаторов Гельмгольца увеличивается вносимый фазовращателем фазовый сдвиг. Однако наличие скачка импедансов на стыке волноводов приводит к увеличению отраженной от фазовращателя волны, что в свою очередь ведет к уменьшению коэффициента пропускания. При используемых в конструкции размерах изменение амплитуды выходного давления не превышает 30\%. Внутри каждого резонатора располагаются связанные между собой поршни высотой $35 \mathrm{~mm}$. Положение поршня фазовращателя задается ведущим винтом М5 $\times 0.8-50$ с помощью биполярного шагового двигателя 25GBC12 с редуктором 1:12. Пространство между поршнем и цилиндром заполнено смазкой, которая обеспечивает плавное перемещение поршня, а также несколько компенсирует неплотное примыкание поршней к цилиндрам. При использовании двигателя в полушаговом режиме угловой шаг составляет $0.625^{\circ}$. Таким образом, максимальное разрешение при изменении высоты резонаторов $h$ составляет $\sim 1.4 \mu \mathrm{m}$, а точность позиционирования ограничена в основном люфтом вала редуктора шагового двигателя.

Управление измерительной установкой осуществляется с помощью персонального компьютера. За фор- мирование и сбор сигналов отвечает аудиоинтерфейс UMC1820 (Behringer). В качестве измерительных микрофонов используются конденсаторные электретные капсюли ECM-66 (Sony), для которых был изготовлен предварительный усилитель с фантомным питанием $48 \mathrm{~V}$. Управление фазовращателем производится с помощью драйвера шагового двигателя, разработанного на основе микроконтроллера STM32F100C4T6 (STMicroelectronics) и преобразователя интерфейсов FT232RL. Интерфейсная программа, полностью автоматизирующая процесс измерения, написана на языке Python c использованием библиотек PySerial и SoundDevice. Bce элементы фазовращателя, волноводы, корпуса для микрофонов и рупор изготовлены из PLA-пластика (плотность $1.24 \mathrm{~g} / \mathrm{cm}^{3}$ ) методом 3D-печати с точностью $0.2 \mathrm{~mm}$.

Численное моделирование отклика разработанной ячейки фазовращателя проводилось в программном пакете COMSOL Multiphysics. При построении геометрии моделирования предполагалось, что стенки волновода и элементов фазовращателя являются абсолютно жесткими. На выходном сечении второго волновода было задано граничное условие в виде идеально согласованного слоя. На рис. 2 приведены зависимости нормированной амплитуды давления прошедшей через ячейку фазовращателя волны $p_{2}(a)$ и разности фаз между падающей и прошедшей волнами $\Delta \varphi(b)$ от высоты резонатора $h$ и частоты $f$. Из представленных зависимостей следует, что разработанная ячейка фазовращателя позволяет изменить фазу прошедшей волны на любую величину из диапазона 0-2 $\pi$ в диапазоне частот $2500-3000 \mathrm{~Hz}$.

На рис. 2 приведены полученные в результате эксперимента зависимости нормированной амплитуды давления прошедшей через ячейку фазовращателя волны 

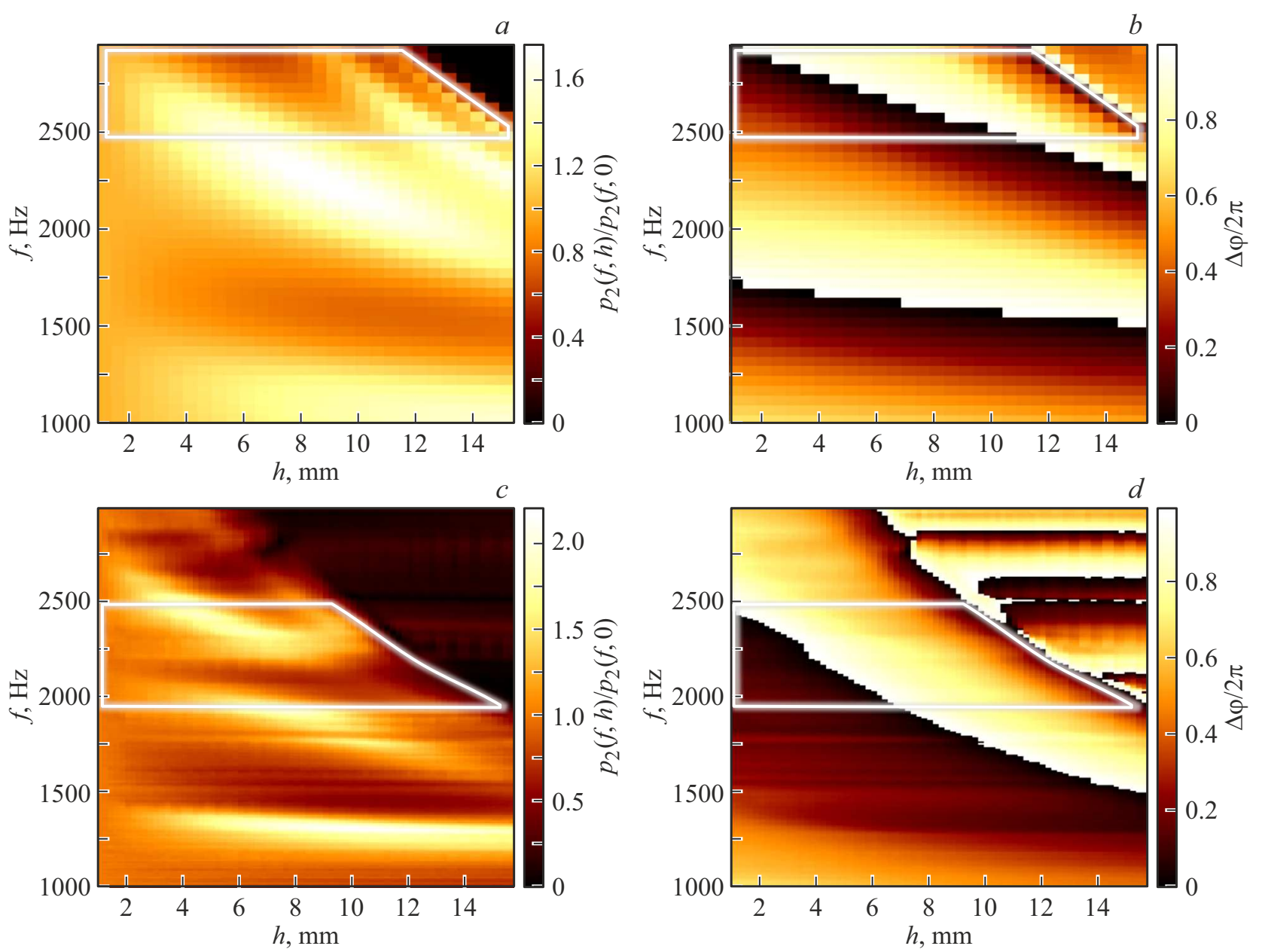

Рис. 2. Зависимости нормированной амплитуды давления на выходе фазовращателя $(a, c)$ и вносимого им фазового сдвига $(b, d)$ от частоты акустической волны $f$ и высоты резонаторов $h$, полученные в результате численного моделирования $(a, b)$ и эксперимента $(c, d)$. Светлой линией выделена область регулирования фазы на $2 \pi$.

$p_{2}(c)$ и разности фаз между падающей и прошедшей волнами $\Delta \varphi(d)$. Видно, что рабочий диапазон изготовленного фазовращателя сместился в более низкочастотную область и эффективное управление фазой осуществляется в диапазоне $2000-2500 \mathrm{~Hz}$. Такое расхождение можно объяснить недостаточно высокой точностью изготовления элементов фазовращателя. Во-первых, сечения горловин резонаторов получаются несколько меньше заданных и могут отличаться от заданных на $0.2 \mathrm{~mm}$ из-за температурной деформации материала и использования технологических „поддержек“, необходимых в процессе 3D-печати методом FDM. Во-вторых, ввиду неплотного примыкания подвижных поршней к стенкам резонаторов, несмотря на наличие смазки, увеличивается активная составляющая импеданса резонатора, связанная с потерями на излучение. Тем не менее наблюдается хорошее качественное соответствие результатов эксперимента и численного моделирования и получен требуемый фазовый сдвиг в интересующем диапазоне.

Разработанный и исследованный фазовращатель может применяться в качестве ячейки перестраиваемой акустической метаповерхности. Разработанная конструкция позволяет осуществлять полный поворот фазы акустической волны. Скорость перестройки ячейки составляет не менее $1 \mathrm{rad} / \mathrm{s}$. Можно ожидать, что пропорциональное масштабирование размера волновода и количества ячеек позволит сформировать оперативно перестраиваемую акустическую метаповерхность для произвольного управления фронтом акустической волны.

\section{Финансирование работы}

Исследование выполнено за счет гранта Российского научного фонда (проект № 19-79-00098).

\section{Конфликт интересов}

Авторы заявляют, что у них нет конфликта интересов. 


\section{Список литературы}

[1] J. Li, C. Shen, A. Díaz-Rubio, S.A. Tretyakov, S.A. Cummer, Nature Commun., 9, 1342 (2018).

DOI: $10.1038 / \mathrm{s} 41467-018-03778-9$

[2] H. Zou, P. Li, P. Peng, Phys. Lett. A, 384, 126151 (2020). DOI: 10.1016/j.physleta.2019.126151

[3] S. Qi, Y. Li, B. Assouar, Phys. Rev. Appl., 7, 054006 (2017). DOI: 10.1103/PhysRevApplied.7.054006

[4] Y. Han, X. Wang, G. Xie, X. Tang, T. Chen, J. Appl. Phys., 127, 064902 (2020). DOI: 10.1063/1.5119408

[5] X. Jiang, Y. Li, B. Liang, J. Cheng, L. Zhang, Phys. Rev. Lett., 117, 034301 (2016). DOI: 10.1103/PhysRevLett.117.034301

[6] S.-D. Zhao, A-L. Chen, Y.-S. Wang, C. Zhang, Phys. Rev. Appl., 10, 054066 (2018). DOI: 10.1103/PhysRevApplied.10.054066

[7] L. Bai, G.Y. Song, W.X. Jiang, Q. Cheng, T.J. Cui, Appl. Phys. Lett., 115, 231902 (2019). DOI: 10.1063/1.5125735

[8] Z. Tian, C. Shen, J. Li, E. Reit, Y. Gu, H. Fu, S.A. Cummer, T.J. Huang, Adv. Funct. Mater., 29, 1808489 (2019). DOI: $10.1002 / \mathrm{adfm} .201808489$

[9] Z. Chen, S. Shao, M. Negahban, Z. Li, J. Phys. D: Appl. Phys., 52, 395503 (2019). DOI: 10.1088/1361-6463/ab2abd 